\title{
The Interplay Between Rainfall and Vegetation
}

\author{
John Boland ${ }^{a}$ \\ ${ }^{\text {a }}$ School of Information Technology and Mathematical Sciences and the Barbara Hardy Institute, University \\ of South Australia, Mawson Lakes Boulevard, Mawson Lakes, SA, 5095, Australia \\ Email: john.boland@unisa.edu.au
}

\begin{abstract}
:
There have been numerous studies detailing the deleterious effects of vegetation clearance on rainfall totals. Junkermann et al (2009) report on trends in rainfall in Western Australia. They state that

The western tip of the continent has experienced a reduction of precipitation by about $30 \%$ (from an average of $325 \mathrm{~mm} / \mathrm{a}$ ) since the 1970s, attributed to a change in the large scale surface pressure patterns of the southern ocean (Allan and Haylock, 1993; Smith et al., 2000) with a concurrent reduction in surface water fluxes (Bates et al., 2008).

We focus for the remaining investigation on South Australia, starting first with details of an investigation of rainfall trends in Cummins, on Eyre Peninsula, $34.26^{0} \mathrm{~S}, 135.73^{0} \mathrm{E}$. Despite some perceptions of increased rainfall in the region, I found a significant decrease in rainfall if you compared before and after 1975, roughly mirroring the Western Australian experience, even if not as extreme. Noteworthy is the fact that the land clearance in this area took place principally from the 1950s (Sindicic 2002), substantially later than in some other parts of South Australia.

The perception is that the extensive plantings on the Monarto plateau in the 1970s has led to increased rainfall on the plateau and close by. Unfortunately, the only official weather station on the plateau is at the Monarto Zoo, and has only been in operation sporadically. However there are official stations at Murray Bridge $\left(35.12^{\circ} S, 139.27^{\circ} \mathrm{E}\right)$ and Callington $\left(35.12^{\circ} \mathrm{S}, 139.04^{\circ} \mathrm{E}\right)$ adjacent. Gallant et al (2007) studied rainfall trends from 1910-2005 in six regions of Australia. In their Southeast region, which includes this study area, their conclusion was that there has been a significant decrease in annual total rainfall of $20 \mathrm{~mm}$ per decade since 1950 (that) stems mainly from decreases during autumn. It is in this context that we present results from rainfall trend analysis for these stations and two further from the Monarto plateau It would appear that these two locations at the edge of the plateau are going against the trend, with increasing rainfall if one compares the period pre 1989 with that after, though not at a significant level. The year 1989 was chosen as this is one decade after the Monarto plantings. On the other hand, the trends at Mt Barker and Tailem Bend are consistent with the findings of Gallant et al (2007) of a diminishing rainfall in this area of the country, though not at as great a rate as they report.

Thus, there appears to be some evidence in Australia of the influence of introducing vegetation on rainfall as well as the more easily supported evidence of lowering of rainfall with land clearance. One must be guarded in this conclusion as there are always confounding factors, for instance changing weather patterns with climate change being one. But it does influence us to conduct more research into the topic.
\end{abstract}

Keywords: Rainfall models, land-use, revegetation 


\section{INTRODUCTION}

There have been numerous studies detailing the deleterious effects of vegetation clearance on rainfall totals. Junkermann et al (2) report on trends in rainfall in Western Australia. They state that

The western tip of the continent has experienced a reduction of precipitation by about $30 \%$ (from an average of $325 \mathrm{~mm} / \mathrm{a}$ ) since the 1970s, attributed to a change in the large scale surface pressure patterns of the southern ocean (Allan and Haylock, 1993; Smith et al., 2000) with a concurrent reduction in surface water fluxes (Bates et al., 2008).

To illustrate this change over time, see Figure 1. The mean annual rainfall for Perth Airport up to 1975 was 836 $\mathrm{mm}$. and from 1975 on was $721 \mathrm{~mm}$. A statistical test was run to see if the mean before 1975 is significantly higher than after and it was found to be significant at a p-value of $<0.01$.

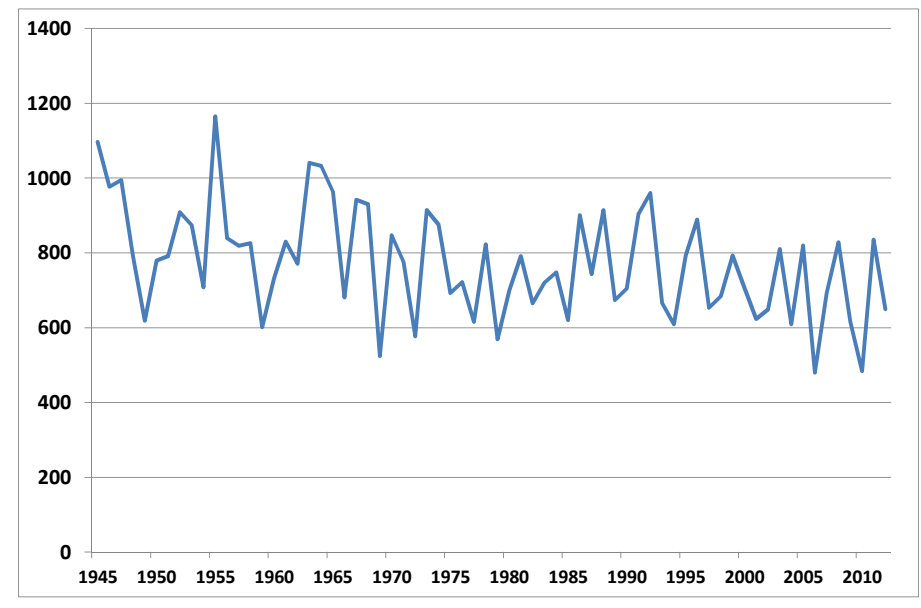

Figure 1. Annual rainfall totals for Perth Airport from 1945

While this large scale phenomenon has been going on, there would seem to have been more local changes as well. It is necessary to give some background on land use changes in the region. At essentially the state boundary between Western Australia and South Australia, there is the approximately $1500 \mathrm{~km}$ Vermin Proof Fence (formerly referred to as the Rabbit Proof Fence) erected in the early part of the 20th century. On the western side the land was predominantly cleared for agriculture, whereas the eastern side is natural vegetation. Sadler (5) found that there has been a shift in precipitation from the agricultural regions to the regions of natural vegetation with an increase of about $20 \%$. Junkermann et al (2) conducted atmospheric experiments above both the agricultural regions and the area of natural vegetation, attempting to understand the mechanisms behind the differential changes in rainfall. They concluded that extra cloud condensation nuclei (CCN) were generated over the agricultural areas due to salt lake geochemistry. The extra aerosols mean that there is an increase in cloud droplets competing for condensable water, thus depressing precipitation. This phenomenon does not occur over the areas of natural vegetation, resulting in a decoupling of the water cycle on a regional basis. The deforestation is thus linked to a reduction in rainfall. This significant result gives credence to the premise that land use change in the form of clearance reduces rainfall, but can the opposite be true?

Chikoore and Jury (1) present an interesting discussion of this topic. They focus on understanding the role of vegetation in the African climate system. They quote studies that show that vegetation growth and distribution are largely determined by climate $((8),(7))$. They also refer to vegetation and land use feedbacks on climate $((9),(7))$. Their specific tasks were twofold. One was to determine if greening caused by one rainfall event produced evapotranspiration that affects the next wet spell. The second was to understand if vegetation could help, in their terms, "anchor" cloud bands regardless of external forcing by large scale circulation and heating anomalies. They found positive answers using means such as principal component analysis to support conjectures in both cases.

Our task is to examine the interplay between vegetation and rainfall in South Australia, and we will give evidence to support the depletion of rainfall through land use change, and also that increased vegetation can 
enhance rainfall, if placed advantageously.

\section{RAINFALL TRENDS ON EYRE PENINSULA}

In this section, we will give details of an investigation of rainfall trends in a particular region of South Australia, Cummins, on Eyre Peninsula, $34.26^{0} S, 135.73^{\circ} \mathrm{E}$. A subsequent section will deal with trends in and around the Monarto region, $35.08^{\circ} S, 139.13^{\circ} \mathrm{E}$, of South Australia. Note that in all teh analysis in this paper, we use annual rainfall totals. Seasonal analysis was also performed and, somewhat surprisingly to the author, the results by season did not show any significant difference from the annual analysis. Also, in this study, no account was taken of any extraneoous variables such as temperature trends or ENSO for example and their possible connection with rainfall. This will be examined in future work.

There is a history of land clearance on Eyre Peninsula, primarily for agricultural activities. Quoting from the Cummins-Wanilla Basin Catchment Management Plan (6), Native vegetation covers only $6 \%$ or $50 \mathrm{~km}^{2}$ of the Basin with the majority of the land utilised for various agricultural purposes. The Cummins-Wanilla Basin, as is the Eyre Peninsula as a whole, is of high botanical significance. There occurs a number of species and associations of species of high conservation significance. South of Cummins was once dominated by Low Open Forest, including Eucalyptus cladocalyx (sugar gum) with an understorey of Xanthorrhoea sp. (yacca), and various Acacia sp. (wattle). Closer to Cummins the community was predominantly Open Scrub with various Mallee type Eucalyptus sp. as well as Melaleuca lanceolata (dryland tea tree) (6).

As part of an Australian Research Council Discovery Indigenous Researcher Development grant, one of the prime areas of activity has been to identify specific locations where revegetation projects may be able to enhance rainfall, particularly where there is evidence of rainfall decline. Interestingly, two members of the project team interviewed some people in the Cummins region as to their views on the project and what they would think about attempting to increase the rainfall in the region. The reaction of two of the people interviewed are described below:

One chap said, "We have lots of water lying on the ground so we don't need any more rain." Another woman said, "We don't need any more rain, we have enough now"

The question arises then as to whether, as these statements seem too imply, the rainfall has actually increased in the Cummins region over time. To begin the analysis, Figure 2 shows the annual rainfall totals for Cummins from 1915-2004. Later years were excluded because of missing months of data. Coincidentally, many of the latter years coincided with a severe drought and they may have biased the analysis. Superimposed on the figure is the exponentially smoothed version of the rainfall totals constructed using

$$
Y_{t}=\alpha X_{t}+(1-\alpha) Y_{t}, \quad Y_{0}=X_{0}, 0<\alpha<1
$$

$X_{t}$ is the original data series and if $\alpha=1$ we get the original series. So, higher values of $\alpha$ decrease the level of smoothing. From the figure it appears that there may be a downward trend to the totals. To determine whether there is, we perform a comparison of the totals before and after 1975, with the mean rainfall before being $440 \mathrm{~mm}$. and after being $395 \mathrm{~mm}$. This does not seem as dramatic a shift as in Western Australia, but still may be a significant change. A test was performed with the following hypotheses:

$$
\begin{array}{rll}
H_{0} & : & \mu_{1}=\mu_{2} \\
H_{1} & : & \mu_{1}>\mu_{2} \\
\alpha & =0.05
\end{array}
$$

The null hypothesis was rejected with a p-value of 0.014 . Thus, evidence of a statistically significant reduction in rainfall exists. This appears at odds with the views expressed above by the two people interviewed. How can we have such a contradiction - an appearance of too much, or at least sufficient, rain and scientific evidence of depletion in rainfall? One can hypothesise that, as in the Western Australian example given in the Introduction, there is a link between the rainfall decline and land clearance. Even more significantly, conjectures can be formed as to the disjunction between the reality of depletion of rainfall and the perception of waterlogging.

It is easy to imagine that with the clearance of land there will be less interception of the rain that falls, that is more runoff. This runoff can tend to pool in regions where the soil structure is such that there is little soakage, 
that is where you have clay soils or indeed, silting up over time because of runoff of material as well as the rainfall. What is happening is that the people who believe there is sufficient or even an increase in rainfall are seeing only the superficial markers, the pooling. They are not seeing the decline in rainfall, it is happening at longer time scales than their levels of perception allow for. If they were truly perceptive, they would notice the decline in rainfall and then ask the truly pertinent question, why is there more pooling with less rain! Common sense perceptions that are couched within cultural understandings don't necessarily include an analysis of environmental change. Noteworthy is the fact that the land clearance in this area took place principally from the 1950s (6), substantially later than in some other parts of South Australia.

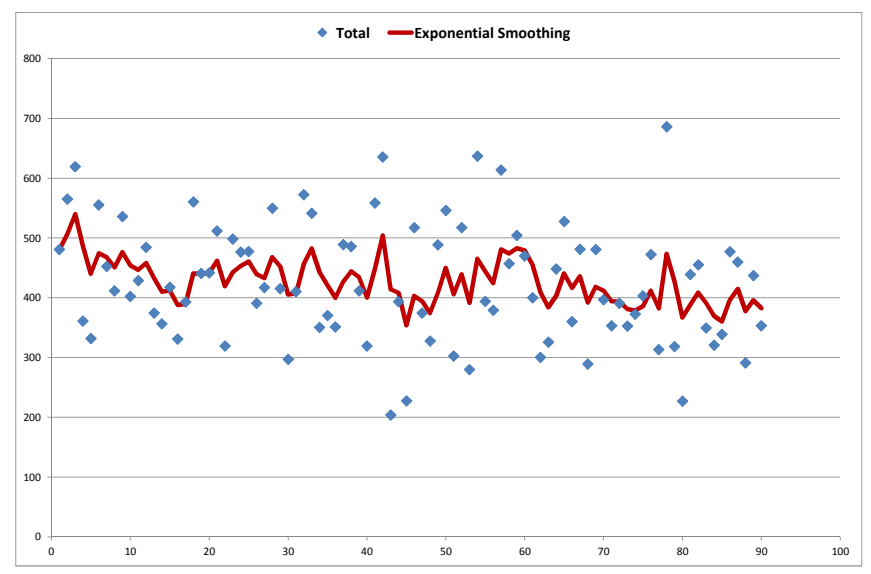

Figure 2. Annual rainfall totals for Cummins with smoothed trend

\section{RAINFALL TRENDS AT MONARTO AND SURROUNDING AREAS}

The perception is that the extensive plantings on the Monarto plateau in the 1970s has led to increased rainfall on the plateau and close by. Unfortunately, the only official weather station on the plateau is at the Monarto Zoo, and has only been in operation sporadically. However there are official stations at Murray Bridge $\left(35.12^{\circ} \mathrm{S}, 139.27^{\circ} \mathrm{E}\right)$ and Callington $\left(35.12^{\circ} \mathrm{S}, 139.04^{\circ} \mathrm{E}\right)$ adjacent. The structure of the analysis in this section will be to examine the annual trend in rainfall before and after the intervention, that is the planting of the vegetation. This is not precisely what will be done, since we will allow some time after the plantings for establishment. Since the last of the organised plantings was in 1979, we will use 1989 as the change year, the year we will assume that there has been sufficient establishment. We will compare what is happening at these two stations two with what is happening at two others, one further away to the East (Tailem Bend $35.26^{\circ} S, 139.46^{\circ} \mathrm{E}$ ) and one to the West ( Mt. Barker $-35.07^{\circ} S, 138.86^{\circ} \mathrm{E}$ ). These are in areas where there wasn't the same level of interference during this time. It should be noted that all of the area in which these four stations are located underwent substantial clearing prior to the 1970s.

Gallant et al (3) studied rainfall trends from 1910-2005 in six regions of Australia. In their Southeast region, which includes this study area, their conclusion was that there has been a significant decrease in annual total rainfall of $20 \mathrm{~mm}$ per decade since 1950 (that) stems mainly from decreases during autumn. It is in this context that we present results from rainfall trend analysis for these four stations.

We examine Murray Bridge rainfall over the whole period of record first. This is displayed in Figure 3. From this diagram, it appears that contrary to the conclusions in (3), the rainfall in latter years at Murray Bridge has either maintained the same level or indeed slightly risen. To test this premise we divide the data into two sets, pre 1989 and from 1989 onwards. The mean rainfall before 1989 was 341 mm and 373 after. We then tested the hypotheses.

$$
\begin{aligned}
H_{0} & : \quad \mu_{1}=\mu_{2} \\
H_{1} & : \quad \mu_{1}<\mu_{2} \\
\alpha & =0.05
\end{aligned}
$$


For this test, the $\mathrm{p}$-value $=0.073$. In essence the null hypothesis of equal rainfall before and after 1989 cannot be rejected, but the p-value is quite close to the level of significance, and so the conclusion can be regarded as tentative. Indeed, if one changed the hypothesis test where one were evaluating the conjecture from (3), that the annual rainfall was $20 \mathrm{~mm}$ greater before 1989 versus the rainfall difference was less than that, the p-value for that test is 0.01 . In any case, one can conclude that the rainfall is either similar before and after 1989 or greater after, rather than the expectation of diminishing rainfall.

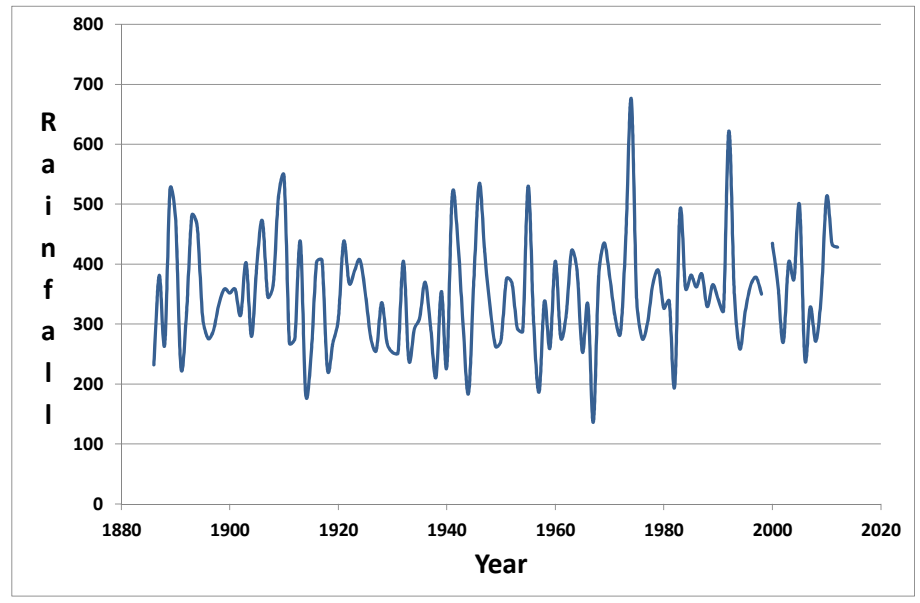

Figure 3. Annual rainfall totals for Murray Bridge from 1886

Let's now turn to the other station in close proximity to the Monarto plateau, that of Callington. A similar set of tests shows not disparate results, with there being little statistical likelihood that the rainfall could have decreased after 1989 and a not significant but indicative chance of an increase, at least when compared to the previous few decades. See Figure 4 for an illustration of this. One might surmise that after land clearance the rainfall decreased and that it is now being restored to historical levels. The mean rainfall before 1989 was 369 $\mathrm{mm}$ and 400 after.

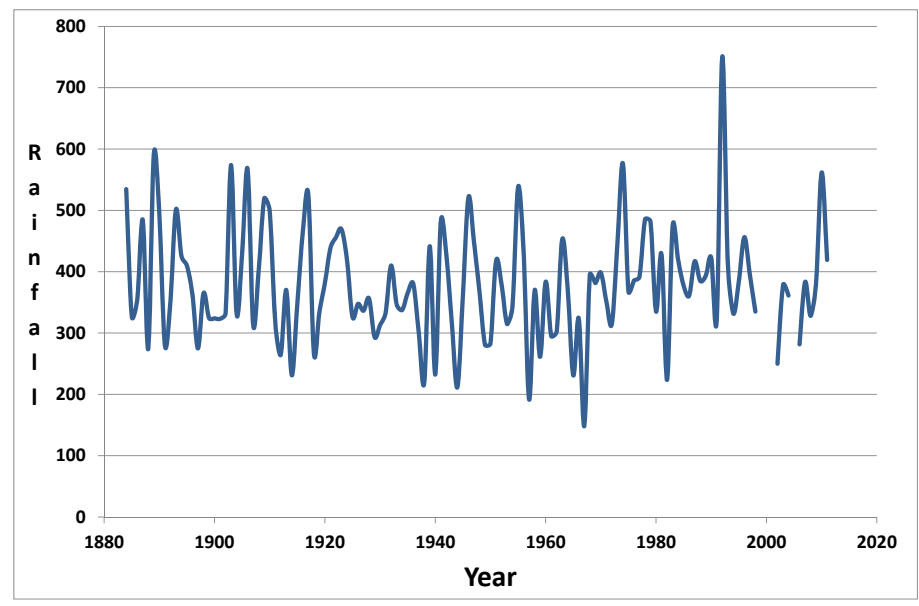

Figure 4. Annual rainfall totals for Callington from 1884

It would appear that these two locations at the edge of the plateau are going against the trend identified by (3). It still could be that the entire region is following the same trend over time. In this case, there would be no argument for the conjecture that the increase in vegetation has aided the total rainfall. To check on this, we 
will examine the trends over time for the two locations more removed from the plateau. First, let us look at the time series of annual rainfall at Mt Barker, as shown in Figure 5. An hypothesis test for equal rainfall before 1989 versus less after has a p-value of 0.103 . So there is a lower average rainfall after of $727 \mathrm{~mm}$ versus 775 before but it is not significantly lower.

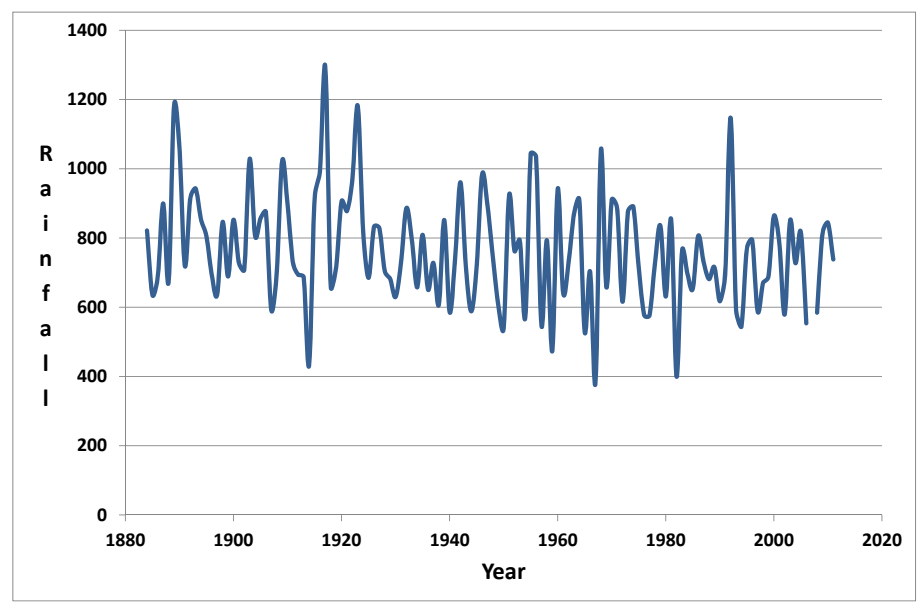

Figure 5. Annual rainfall totals for Mt Barker from 1884

We shall now move to examining a town east of the plateau, Tailem Bend, for rainfall trends. The mean rainfall before 1989 was $380 \mathrm{~mm}$ and after was 348, as illustrated in Figure 6. An hypothesis test of the mean rainfall being the same before and after 1989 versus being less after was not rejected with a p-value of 0.069 . This was in a way similar to the test for Murray Bridge but with opposite alternate hypothesis, being greater after 1989 at Murray Bridge and less after 1989 at Tailem Bend, even though the two locations are only $20 \mathrm{~km}$ apart.

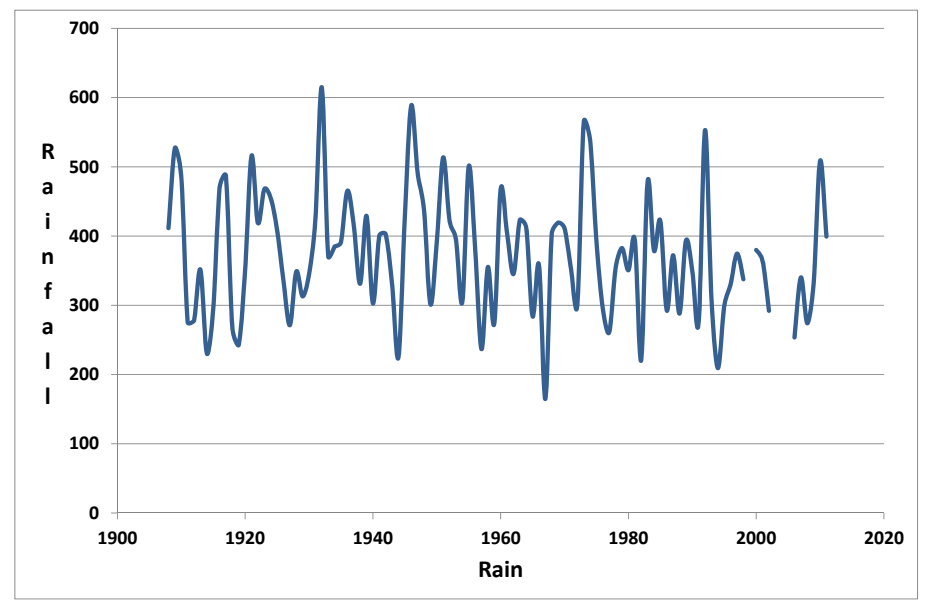

Figure 6. Annual rainfall totals for Tailem Bend from 1908

To summarise the rainfall analysis at the four locations, there is insufficient statistical evidence to conclude any difference in the mean rainfall before and after 1989 at any station. There is however, a definite pattern in the results. The trends at Mt Barker and Tailem Bend are consistent with the findings of Gallant et al (3) of a diminishing rainfall in this area of the country, though not at as great a rate. Estimates of the change per decade in rainfall at the four stations are given in Table 1. Note that, as expected, the slopes are not statistically significant, but on the other hand are actual estimates of change. Also, the changes are positive near the plateau 
and negative further away, consistent with an influence there. And, as has been emphasised, if we test that the changes are consistent with the findings of Gallant et al (3), we find that this hypothesis is rejected.

\begin{tabular}{|c|c|c|c|}
\hline Murray Bridge & Callington & My Barker & Tailem Bend \\
\hline 9.5 & 9.6 & -6.8 & -8.2 \\
\hline
\end{tabular}

Table 1. Changes in rainfall in mm per decade at the four locations

\section{Conclusion}

I have tried to try to add some knowledge to the interplay between vegetation and rainfall. As was stated, there has been a significant amount of work on how rainfall can diminish after clearance of large areas of vegetation. There has been less work reported on how rainfall might be enhanced by strategic planting schemes. What I mean by strategic is selection of sites that will aid in interference with weather patterns in order to add to the rainfall totals where they are needed. Fortuitously, the plantings that were made in the Monarto area in the 1970s seem to have been by chance of great enough extent and in a sensible area to be able to enhance the rainfall in the surrounding towns of Murray Bridge and Callington. In the future, our plan is to pursue strategic planting schemes near Cummins on Eyre Peninsula. There will be a separate side to this endeavour. It involves the Cummins Area School, and will help provide school children with the knowledge to be able to read the landscape better than some of their elders.

\section{ACKNOWLEDGEMENT}

This work is supported by ARC Discovery Indigenous Researcher Development Grant DI110100028 - Indigenous knowledge: water sustainability and wild fire mitigation

\section{REFERENCES}

[1] Hector Chikoore and Mark R. Jury (2010) Intraseasonal Variability of Satellite-Derived Rainfall and Vegetation over Southern Africa, Earth Interactions, Volume 14 Paper No. 3.

[2] W. Junkermann, J. Hacker, T. Lyons, and U. Nair (2009) Land use change suppresses precipitation, Atmos. Chem. Phys., 9, 6531-6539.

[3] Gallant A., Hennessy K., Risbey J. (2007) Trends in rainfall indices for six Australian regions: 19102005, Aust. Met. Mag., 56, pp. 223-239.

[4] T J Lyons (2002) Clouds prefer native vegetation, Meteorology and Atmospheric Physics, 80, pp. 131140.

[5] Sadler, B. (2002) Climate variability and change in south west Western Australia, Indian Ocean Climate Initiative Panel, c/-Department of Environment, Water and Catchment Protection, WA, http://www.waterandclimateinformationcentre.org/resources/8012007 IOCI2002.pdf.

[6] Mark Sindicic and the STREAMCARE Working Group (2002) Cummins-Wanilla Basin Catchment Management Plan.

[7] Wang G (2004) A conceptual modeling study on biosphere-atmosphere interactions and its implications for physically based climate modeling. Journal of Climate, 17, 25722583.

[8] Woodward F I (1987) Climate and plant distribution, Cambridge: Cambridge Univ. Press.

[9] Zeng, N., J. D. Neelin, K.-M. Lau, and C. J. Tucker, (1999) Enhancement of interdecadal climate variability in the Sahel by vegetation interaction. Science, 286, 1537-1540. 